\title{
METODOLOGIA SIMPLEX CENTROIDE PARA OTIMIZAÇÃO DA EXTRAÇÃO DE FLAVONOIDES DAS FOLHAS DE Eugenia uniflora Linn
}

\author{
I. C. F. BEZERRA ${ }^{1}$, R. T. M. RAMOS ${ }^{1}$, M. R. A. FERREIRA ${ }^{1}$ e L. A. L. SOARES ${ }^{1}$ \\ ${ }^{1}$ Programa de Pós-graduação em Inovação Terapêutica, Universidade Federal de Pernambuco, \\ Centro de Ciências Biológicas \\ E-mail para contato: isabelle.ferraz@outlook.com.br
}

\begin{abstract}
RESUMO - Eugenia uniflora Linn, popularmente conhecida como pitangueira, é uma espécie com potencial terapêutico devido as suas propriedades biológicas, sendo utilizada na medicina tradicional como antipirético, antihipertensivo, antirreumático e antimicrobiano. Diversas destas atividades têm sido atribuídas aos flavonoides presentes na espécie, sendo considerados os marcadores e alvos de estudos tecnológicos. Neste sentido, estudos sobre a concentração e a extração destas substâncias através de desenhos experimentais figuram como alternativa tecnológica para obtenção de produtos ricos em flavonoides. Assim, planejamentos de misturas representam uma importante ferramenta para eleição de novos sistemas para extração. A partir do planejamento simplex centroide, foram obtidos 15 extratos, caracterizados quanto ao resíduo seco, teor de flavonoides e eficiência de extração. Após análise dos dados, foi possivel obter modelos matemáticos que permitiram a previsão de novas misturas com a eficiência desejada, sendo responsável pela produção de extratos contendo 1,36\% de flavonoides totais usando a mistura quaternária de água:metanol:etanol:acetona 46:13:18:26 (v/v/v/v) modelada através de equações matemáticas e pelos parâmetros de desirability.
\end{abstract}

Palavras chave: Pitanga. Planejamento de Misturas. Padronização.

\begin{abstract}
Eugenia uniflora Linn, popularly known as pitangueira, is a species with therapeutic potential due to its biological properties, being used in traditional medicine as antipyretic, antihypertensive, antirheumatic and antimicrobial. Several of these activities have been attributed to flavonoids present in the species, being considered markers and targets for technological studies. Thus, studies on the concentration and extraction of these substances through experimental designs are a technological alternative to obtain products rich in flavonoids. So, mixture designs represent an important tool for the selection of new extraction systems. From the simplex centroid planning, 15 extracts were obtained, which were characterized by dry residue, flavonoids content and extraction efficiency. After the data analysis, it was possible to obtain mathematical models that allowed the prediction of new mixtures that had the desired efficiency, being responsible for the production of extracts containing $1.36 \%$ of total flavonoids using the quaternary mixture of water:methanol:ethanol:acetone 46:13:18:26 acetone
\end{abstract}


$(v / v / v / v)$ modeled by mathematical equations and desirability parameters.

Keywords: Pitanga. Mixture design. Standardization.

\section{INTRODUÇÃO}

Eugenia uniflora Linn (Myrtaceae) é uma espécie com ampla utilização na medicina tradicional devido as propriedades biológicas, como: antimicrobiana, antihipertensiva, antirreumática, antioxidante e anti-inflamatória (RATTMANN et al., 2012; GARMUS et al., 2015). Algumas destas atividades são atribuídas aos polifenois, principalmente aos flavonoides (RATTMANN et al., 2012; RAMOS et al., 2017). Diante disso, a concentração e a manutenção da concentração destes compostos torna-se relevante para assegurar a segurança e eficácia assim como para o desenvolvimento de produtos derivados desta espécie.

Para otimizar os processos extrativos e obter maiores concentrações dos marcadores, os estudos acerca de fatores e variáveis que podem ter influência sobre o processo são fundamentais (BARROS NETO; SCARMINIO; BRUNS, 2010). Dentre os fatores que podem influenciar o processo extrativo encontram-se os solventes ou sistemas de solventes empregados na extração, sendo estes os principais responsáveis pelo perfil químico dos extratos (DICIAULA et al., 2014, BLAINSKI et al., 2017). Neste sentido, os desenhos experimentais como o planejamento de misturas, compõem uma estratégia apropriada para investigar os efeitos das misturas sobre a eficiência da extração. Portanto, o objetivo deste trabalho foi maximizar a extração de flavonoides das folhas de E. uniflora empregando desenhos experimentais de planejamento de misturas do tipo simplex centroide.

\section{MATERIAIS E MÉTODOS}

\subsection{Coleta, estabilização e produção dos extratos}

$\mathrm{O}$ material vegetal foi coletado em Igarassu-PE e identificada no instituto agronômico de Pernambuco sob número de tombamento 91670. O material foi estabilizado em estufa de circulação de ar $\left(82 / 480\right.$, Lucadema $\left.{ }^{\circledR}\right)$ durante $48 \mathrm{~h}$ à $40{ }^{\circ} \mathrm{C}$. Em seguida, as folhas foram trituradas em moinho de facas (Tipo Willye TE-680, Tecnal ${ }^{\mathbb{B}}$ ). A influência de solventes extratores foi avaliada através de planejamento simplex centroide, no qual foram preparados extratos utlizando água, metanol, etanol, acetona e as misturas binárias, ternárias e quaternárias destes solventes, totalizando 15 extratos. Os extratos foram obtidos pelo método extrativo por turbólise (Liquidificador Industrial, Metvisa ${ }^{\circledR}$ ), em 4 ciclos de 30 segundos, com intervalos de 5 minutos, na proporção droga: solvente $10 \%$ (p/v) (RAMOS et al., 2017).

\subsection{Avaliação de teor de resíduo seco, flavonoides totais e eficiência de extração}

Os extratos foram caracterizados pela determinação de resíduo seco (RS) em balança de infravermelho (ID50, Marte ${ }^{\circledR}$ ), teor de flavonoides totais (TFT) por espectrofotometria UVVis através da complexação com cloreto de alumínio $\left(\mathrm{AlCl}_{3}\right)\left(\mathrm{AJX}-1900\right.$, Micronal $\left.{ }^{\mathbb{R}}\right)$ e a relação entre o teor de flavonoides com o teor de sólidos, denominada eficiência de extração (EF). As análises foram realizadas em triplicata e os dados resultantes foram analisados com auxílio dos softwares Statistica ${ }^{\circledR}$ e Minitab ${ }^{\circledR}$.

\section{RESULTADOS E DISCUSSÃO}

Considerando o resíduo seco, os dados demonstraram melhor desempenho para as misturas água:acetona $50 \%(\mathrm{v} / \mathrm{v})(\mathrm{RS}=3,45 \%(\mathrm{~m} / \mathrm{v}))$; e, quaternária água:metanol:etanol:acetona, $25 \%(\mathrm{v} / \mathrm{v} / \mathrm{v} / \mathrm{v})(\mathrm{RS}=3,55 \%,(\mathrm{~m} / \mathrm{v}))$. O maior rendimento em flavonoides totais foi observado nas 
mesmas misturas: água:acetona $50 \%(\mathrm{v} / \mathrm{v}) \quad(\mathrm{TFT}=1,34 \%)$ e mistura quaternária água:metanol:etanol:acetona 25\% (v/v) $(\mathrm{TFT}=1,31 \%)$. Nestes dois parâmetros não foram evidenciadas diferenças estatísticas significativas entre os melhores resultados. Por fim, os dados da eficiência de extração indicaram que os extratos preparados utilizando metanol $(\mathrm{EF}=0,411)$ e as misturas terciárias água:metanol:etanol 33\% (v/v) $(\mathrm{EF}=0,427)$ e metanol:etanol:acetona $(\mathrm{EF}=0,438)$ apresentaram melhor razão resíduo/teor; entretanto, apenas a mistura água:metanol:etanol apresentou resultados vantajosos para teores de resíduo e flavonoides.

A avaliação conjunta dos dados evidenciou o efeito sinérgico dos solventes, cuja performance foi incrementada nas misturas em comparação com os solventes puros, em especial nas misturas secundária (água:acetona); terciária (água:metanol:etanol) e quaternária (água:metanol:etanol:acetona). Para obter a equação matemática que melhor descreve as respostas, foram avaliados diferentes modelos (linear, quadrático e cúbico).

Neste sentido, o modelo cúbico demonstrou ser o mais adequado para descrever as respostas obtidas; e, a partir dos modelos de previsão e dos parâmetros de desirability (figura 1), 7 novas misturas foram preparadas e caracterizadas segundo teores de sólidos, de flavonoide e eficiência de extração.

Figura 1 - Gráficos de desirability para a composição da mistura quaternária de água:metanol:etanol:acetona $(0,45: 0,13: 0,18: 23, \mathrm{v} / \mathrm{v} / \mathrm{v} / \mathrm{v})$ e previsão de teores de resíduos, flavonoides, eficiência de extração de flavonoides.

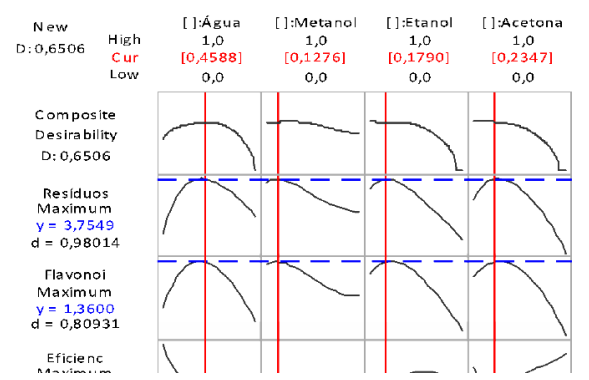

Após análise observou-se que a mistura quaternária de água:metanol:etanol:acetona (46:13:18:23, $\mathrm{v} / \mathrm{v} / \mathrm{v} / \mathrm{v}$ ) apresentou na resposta de teor manutenção dos teores de flavonoides e resíduo (TFT= 1,36\%; $\mathrm{m} / \mathrm{v}$; RS $=3,49 \% ; \mathrm{m} / \mathrm{v}$ ) obtidos pelas misturas de maior eficiência. Entretanto, esta mistura apresentou-se mais vantajosa (em relação as misturas de melhor performance) por aprentar maior eficiência de extração $(\mathrm{EF}=0,395)$ e incremento significativo no teor de outros marcadores polifenólicos (aumento no teor de taninos em relação à todas as misturas testadas), evidenciando a influência sinérgica dos quatro solventes avaliados. Além disso, apresenta elevada proporção de água o que pode favorecer os processos de secagem (etapa seguinte a extração), por evitar a adição de água e reduzir o tempo gasto na remoção de solventes orgânicos para o processo de liofilização, além de aumentar a segurança em processos de secagem que utilizam temperatura (spray drying).

\section{CONCLUSÃO}

Nesse contexto é possível concluir que o planejamento simplex centroide atua como uma ferramenta eficaz para a avaliação e seleção de novos sistemas de solventes, sendo adotada com sucesso para preparação de extratos das folhas de Eugenia uniflora, sendo responsável pela obtenção de maior teor de flavonoides com elevada concentração de água e baixa concentração dos solventes orgânicos presentes na mistura, tornando viável os processos de secagem posteriores que utilizem temperaturas elevadas (spray 
drying). Dessa forma, tais resultados constituem uma importante etapa na padronização dos processos de obtenção de extratos da espécie.

\section{REFERENCIAS}

BARROS NETO, B.; SCARMINIO, I. S.; BRUNS, R. E. Como Fazer Experimentos: Pesquisa e Desenvolvimento na Ciência e na Indústria. Bookman Editora, 2010.

BLAINSKI, A.; GIONCO, B.; OLIVEIRA, A. G.; ANDRADE, G.; SCARMINIO, I. S.; SILVA, D. B.; DE MELLO, J. C. P. Antibacterial activity of Limonium brasiliense (Baicuru) against multidrug-resistant bacteria using a statistical mixture design. J. Ethnopharmacol., v. 198, p. 313-323, 2017.

DICIAULA, M. C.; LOPES, G. C.; SCARMINIO, I. S.; DE MELLO, J. C. P. Optimization of solvent mixtures for extraction from bark of Schinus terebinthifolius by a statistical mixturedesign technique and development of a UV-Vis spectrophotometric method for analysis of total polyphenols in the extract. Quím. Nova, v. 37, p. 158-163, 2014.

GARMUS, T.T.; PAVIANI, L.C.; QUEIROGA, C.L.; MAGALHÃES, P.M.; CABRAL, F.A. Extraction of phenolic compounds from pitanga (Eugenia uniflora L.) leaves by sequential extraction in fixed bed extractor usingsupercritical CO2, ethanol and water as solventes; $\mathbf{J}$. Supercrit. Fluids 86, 4-14, 2014.

RAMOS, R. T. M.; BEZERRA, I. C. F.; FERREIRA, M. R. A.; SOARES, L. A. L. Spectrophotometric Quantification of Flavonoids in Herbal Material, Crude Extract and Fractions From Leaves of Eugenia uniflora Linn. Pharmacog. Res., v. 9, p. 253-260, 2017.

RATTMANN, Y. D.; DE SOUZA, L. M.; MALQUEVICZ-PAIVA, S. M.; DARTORA, N.; SASSAKI, G. L.; GORIN, P. A.; IACOMINI, M. Analysis of flavonoids from Eugenia uniflora leaves and its protective effect against murine sepsis. Evid-Based Compl. Alt., 2012.

\section{AGRADECIMENTOS}

Os integrantes agradecem a FACEPE (IBPG-0557-4.03/15; APQ-0493- 4.03/14) e ao CNPq (308386/2015-9). 